\title{
Aspectos culturais que dificultam a participação das mulheres na politica eleitoral e sua relação com as esferas público-privada
}

\author{
Cultural aspects that make it difficult for women to participate in \\ electoral politics and the relationship with the public-private spheres
}

\section{Simone Lolatto}

\section{Resumo}

O objetivo deste artigo é lançar uma breve análise sobre o processo de exclusão das mulheres dos espaços públicos, associado a componentes culturais, conformando uma baixa participaçáo de mulheres na política eleitoral. Para tanto se recorreu a um levantamento bibliográfico a partir da pesquisa realizada durante o desenvolvimento da tese de doutorado da autora. São feitas reflexóes acerca da dicotomia das esferas pública e privada, sobre a importância da representaçáo descritiva do ponto de vista da democracia de gênero, mas, fundamentalmente, como o processo de empoderamento e a identificação de mais mulheres parlamentares com os feminismos potencializaria a maior representação substantiva e portanto o compromisso com as reivindicaçóes feministas e as políticas públicas que geram avanços nos direitos para as mulheres.

\section{Palavras-chave}

Desigualdade Política de Gênero; Sub-Representação Política das Mulheres; Participação Feminina na Política Eleitoral Brasileira.

\begin{abstract}
This article presents a critical analysis of the process of women's exclusion from public spaces, associated to cultural components, conforming a low participation of women in electoral politics. For this purpose, a bibliographic search from the data research process employed during the author's doctoral thesis was used. Reflections are made on the dichotomy of the public and private spheres regarding the importance of descriptive participation from the point of view of gender democracy, but fundamentally as the empowerment process and the identification of further parliamentarians women with the feminisms would foster the substantive representation and, therefore, the commitment to feminist demands and public policies that generate advances in women's rights.
\end{abstract}

\section{Keywords}

Gender Political Inequality; Women's Political Under-Representation; Female Participation in Brazilian Electoral Politics. 


\section{Introdução}

A sociedade brasileira experimenta um período de tensão que vem num crescente a partir do desgaste e impeachment da presidenta Dilma Rousseff, sucedido pela ascensão de Michel Temer e posterior vitória eleitoral de Jair Bolsonaro à Presidência da República. Neste cenário, se percebe a agressiva retomada da agenda neoliberal de ajustes estruturais, com cortes de investimentos nas políticas públicas vinculadas aos direitos sociais, perda de direitos trabalhistas e desregulamentação do Estado. Esse contexto impacta fortemente o conjunto da classe trabalhadora e segmentos mais vulneráveis da população, dentre os quais se encontram as mulheres e a população negra.

Para ter legitimidade nas contrarreformas da legislação trabalhista, da previdência social e congelamento por 20 anos de investimentos em políticas como educação, assistência social e saúde pública, é imperativo que o governo federal conte com o voto de deputados/as que compóem o Congresso Nacional e o apoio de um campo político nos espaços do legislativo e do executivo no plano local.

É uma determinada característica que marca esses espaços da política eleitoral - e que interfere na vida econômica e social de toda a população - que este artigo enfoca, tendo como problema central as dificuldades de participação e a baixa representatividade das mulheres nesse lócus, o assustador dado que aponta quase $90 \%$ de homens nos assentos dos parlamentos do país. Objetiva-se, neste sentido, analisar os múltiplos fatores que estruturam tamanha diferença na participação entre mulheres e homens na política eleitoral.

Para tanto, metodologicamente se recorreu a um sucinto levantamento bibliográfico para sustentar a hipótese de que questôes histórico-culturais ainda influenciam fortemente os comportamentos, hábitos, costumes e valores.

Destaca-se, antes de passar propriamente à análise em torno das dificuldades para as mulheres participarem da política eleitoral, o entendimento sobre a categoria gênero e as relações entre homens e mulheres, que, conforme traz Joan Scott (1995), estão baseadas em uma hierarquia de poder proveniente de representações simbólicas sobre a diferença sexual e operam a partir de processos sociais elementares; consequentemente, possíveis mudanças nas relaçóes sociais estáo associadas a mudanças também nas representaçôes de poder. Diante disso, a autora questiona a lógica das relações de gênero e a situação de subordinação das mulheres como sujeitos históricos e políticos. 
A construção de sujeitos, para Castro (1992), se dá sob a construção de identidades múltiplas, náo fixas, que se entrelaçam num processo alquímico, em que os constructos vão se fazendo de um modo que não podem mais ser separados, moldados pelas relações sociais em sistemas estruturantes que determinam o comportamento humano. Nesse sentido, a noção de gênero é parte da alquimia das categorias que compóem um entrelaçar das discriminações e opressões. Sistematiza-se essa compreensão enfatizando que,

Gênero é mais que uma categoria, é uma teoria ampla que abrange hipóteses, interpretaçóes, categorias e conhecimentos relativos ao conjunto de fenômenos históricos construídos em torno do sexo. [...] Por sua vez o sexo e o gênero não estão condicionados um ao outro de forma reducionista; a própria sexualidade é uma diferença construída social, histórica e culturalmente (LISBOA, 2003, p. 20).

Juntamente à clareza deste entendimento, resta elucidar que se recorre aos termos "mulheres"/"homens" para expressar a disparidade na participação político eleitoral, tendo em vista que ainda os dados objetivos nos remetem ao binarismo homem/mulher - quando buscamos estatísticas e/ou aportes bibliográficos para debater as dificuldades enfrentadas historicamente pelas mulheres para participarem tanto da vida pública como especificamente da política eleitoral.

É, pois, sobre essas dificuldades e as interferências de toda uma cultura arraigada (e contestada também) que retém a participação feminina nos espaços de poder, que passaremos a refletir a seguir.

\section{Aspectos culturais acerca da participação das mulheres na politica eleitoral ${ }^{1}$}

Apesar do direito ao voto ter sido uma conquista datada de 1932 no Brasil, apenas nas últimas décadas foi observado um pequeno crescimento numérico da participação e incorporação de mulheres nos espaços de representação política, fato suficiente para que, por sua vez, levante expectativas, tanto sobre o desempenho das mesmas na esfera pública, quanto sobre as consequências disso em relação aos interesses das mulheres.

\footnotetext{
${ }^{1}$ As reflexôes apresentadas neste artigo baseiam-se em parte na pesquisa desenvolvida e apresentada na tese de doutorado da autora, em 2016, na Universidade Federal de Santa Catarina - UFSC.
} 
A cultura política predominante, ao longo da história da humanidade, atribuiu o espaço da esfera pública ao masculino, e muitas são as razões para o baixo percentual de mulheres eleitas em postos de representação, das quais se destacam: as questôes culturais que incentivam o desinteresse das mulheres em ver a política eleitoral como um espaço de atuação também para elas; a sobrecarga de responsabilidades nas tarefas do ambiente intrafamiliar com a casa, as refeições e os cuidados de crianças, pessoas idosas ou adoecidas; as dificuldades no interior dos partidos para que mulheres se apresentem candidatas, já que, aparentemente, se privilegia homens em razão do capital político que majoritariamente acumularam; o sistema eleitoral com características que potencializam o êxito eleitoral para lideranças consolidadas (portanto homens na maioria) e só recentemente definiu cotas para mulheres; as exigências vultuosas de recursos orçamentários para as campanhas eleitorais; o acesso/permanência ao mundo do trabalho formal e remunerado que, associado às posições políticas conservadoras de grande parte da sociedade civil, impõem limitações às mulheres a melhores colocações e cargos de chefia, o que vem muitas vezes associado às demandas da maternidade e junto da família, conforme já mencionado; e outras dificuldades.

Essas questóes se associam e acabam por desencadear uma imensa desmotivação nas mulheres para enfrentarem um cenário tão competitivo como é o da política eleitoral, espaço que foi e permanece ocupado por homens como se, supostamente, a eles pertencesse.

A reivindicação pelo direito das mulheres participarem da política ganha visibilidade nos últimos anos do século XIX, adquire sentido coletivo com a formação de grupos e se prolonga para a contemporaneidade, quando os feminismos buscam transformações na cultura política que, predominantemente, atribuiu o espaço da esfera pública ao masculino.

Excluídas inicialmente do status de cidadãs, juntamente com a população negra, as mulheres foram as últimas a serem aceitas como sujeitos políticos, e tal aceitação somente se deu em razão do grande esforço das sufragistas em diferentes locais do mundo, o que trouxe mudanças nas legislaçôes de cada país, possibilitando que as mulheres adquirissem o direito de votarem e serem votadas. Para Astelarra (2003), o contexto que envolve a ausência das mulheres da vida pública e a questão delas não serem consideradas cidadãs por 20 séculos, advém da democracia grega tradicional, pois 
[...] para os gregos o que dava as pessoas o acesso à cidadania era sua liberdade das 'amarras produtivas e reprodutivas'. Esta liberdade os convertia em pessoas que podiam fazer as coisas acontecerem por que não estavam delimitados pelas necessidades sociais. Por isso tinham a capacidade de intervir e produzir projetos coletivos políticos. Já as mulheres e os escravos se dedicavam a trabalhar na satisfação das necessidades sociais da natureza: reproduzir e comer, e por isso eram dependentes e não podiam ser livres. A falta de liberdade lhes excluía da Ágora, o espaço da política (ASTELARRA, 2003, p. 30).

Com o advento da cristandade, após o século $\mathrm{V}$, a situação para as mulheres não se modificou para melhor. Longe disso, as leituras que se tem avaliam que a cristandade tornou tudo ainda mais difícil para elas, pois passaram a ser retratadas como pecadoras e culpadas pelo fim do paraíso. Conforme a análise de Pinafi (2007), com base nesse entendimento, as mulheres deveriam portar-se com passividade, obediência e submissão aos homens, a fim de buscarem sua salvação depois de tanto pecarem. Enquanto os homens estavam retratados como

[...] seres de grande iluminação capazes de dominar os instintos irrefreáveis das mulheres [...]. Assim a religião judaico-cristã foi delineando as condutas e a 'natureza' das mulheres e incutindo uma consciência de culpa que permitiu a manutenção da relação de subserviência e dependência (PINAFI, 2007, p. 18).

Em fins do século XVI e ao longo do século XVII, com a democracia moderna, o entendimento grego foi sendo novamente aplicado e, com sustentação do que tinha a época sobre as ciências biológicas, se retomava a ideia de que a vida das mulheres destinava-se a que estas fossem mães, se ocupassem do lar, dos filhos, do marido e ficassem restritas ao espaço privado - Oikos -, sendo tais funções incompatíveis com a cidadania. Um homem não livre até poderia chegar a obter os direitos como cidadáo caso conseguisse por algum meio adquirir terras e passar a ser "proprietário", contudo uma mulher "[...] não conseguia alterar sua natureza biológica” (ASTELARRA, 2003, p. 30). Portanto, o que poderia ser uma qualidade positiva e um diferencial poderoso à vida das mulheres em sociedade - a possibilidade de gestar e parir (a natureza biológica) - se tornou uma limitação e foi utilizado para manter a exclusão do gênero feminino da participação na esfera pública e das decisões coletivas. 
Associa-se a essa questão as reflexões de Carole Pateman em torno de sua obra "O Contrato Sexual", quando afirma que este é indissociável do contrato social, gerando uma realidade em que os homens serão pretensamente livres e iguais.

O contrato social é uma história de liberdade; o contrato sexual é uma história de sujeição. O contrato original constitui tanto a liberdade quanto a dominação. A liberdade dos homens e a sujeição das mulheres são criadas por meio do contrato original - e a natureza da liberdade civil não pode ser entendida sem a metade faltante da história, que revela como o direito patriarcal dos homens sobre as mulheres é estabelecido por meio de contrato (PATEMAN, 1988, p. 02).

As formulações em torno da categoria da igualdade, uma meta das sociedades democráticas, ao longo do século XVIII, contraditoriamente funda-se a partir de diversas exclusões (FALCÓN, 2012), desde a concepção de que o sujeito central da democracia não é outro senão aquele se constitui em

[...] homem adulto, branco, cristão, ilustrado, heterossexual, sadio, proprietário. Essa construção tão limitada tem diversas consequências tanto na definição de cidadania como na vida prática. Além disso, o princípio de igualdade está vinculado estreitamente com o de universalidade; se considerarmos a variante gênero, a reformulação seria: todos os homens têm todos os direitos (FALCÓN, 2012, p. 93).

$\mathrm{Na}$ avaliação de Falcón (2012), as mulheres travam uma intensa luta pela cidadania, e, dentre suas primeiras conquistas, no decurso dos séculos XIX e XX, estão os direitos políticos básicos, como votar e ser votada; os direitos civis, como o casamento por sua vontade, e o direito de herança. E, também, os direitos sociais e econômicos, destacadamente o acesso à educação, trabalho remunerado, moradia, dentre outros. Porém, ainda "[...] persiste a ausência de mulheres em cargos de tomada de decisões em diferentes poderes e em órgãos de representação" (FALCÓN, 2012, p. 94), encontrando-se aí um componente quantitativo e outro qualitativo.

Analisa-se a quantidade a partir dos debates em torno das reais condiçóes de igualdade e de democracia que uma sociedade experimenta ao ter, no Brasil, por exemplo, apenas pouco mais de $10 \%$ de mulheres nos assentos parlamentares. Enquanto que a questáo qualitativa avança para o campo das representaçóes descritivas e substantivas em relação à participação das mulheres - seus olhares, engajamentos, experiências, potencialidades - tanto para votaçóes que definem os 
rumos da macropolítica de uma nação como na formulação de legislações que irão impactar a vida das pessoas num município, estado e país.

Além desse debate em torno da categoria igualdade, tem-se em Arendt (2009) que a razão de ser da política não é outra senão a liberdade, e seu domínio de experiência é a ação. Sendo assim, a liberdade do espaço íntimo não teria significação política. Conforme ressalta, a liberdade, em sua acepção original do latim, está ligada ao entendimento de "iniciar/agir", e o reino da ação e do movimento histórico está na vida política. De tal modo, a liberdade ou dominação só se tornam concretas quando mediadas pelas inter-relaçóes na esfera pública, e não na interioridade da vida privada, das relações íntimas circunscritas no ambiente doméstico.

Esta compreensão desenvolvida por Arendt, que atribui uma forte separação entre as esferas pública e privada, vem sendo criticada a partir de estudos que percebem a existência de relaçóes políticas no âmbito privado. Para Phillips (1996), este entendimento de Arendt não contribuiu para dissolver a separação entre público e privado, mas reforçou e manteve oculto um conjunto de questôes que oprimem as mulheres no espaço privado e doméstico - este que seria o lugar das mulheres. Arendt argumenta que no âmbito público estão a política e o social em ação, enquanto no âmbito privado estão as relações "não políticas", ou seja, radicalmente esferas apartadas.

Segundo Phillips (1996), as feministas contemporâneas têm contestado muitos pontos de vista ortodoxos que até pouco tempo atrás separavam os âmbitos público e privado, já que, "[...] excluídas primeiro francamente e depois mais sutilmente das fileiras dos cidadãos plenos, as mulheres têm insistido em suas demandas não só como um problema de justiça, senão em nome de uma visão que transforma o mundo" (PHILLIPS, 1996, p. 15), em função inclusive de vivências que carregam, na medida em que eram edificadas as sociedades e o contexto de exclusão a que foram submetidas.

Para que aconteça uma democratização dos espaços políticos, se faz necessário, por um lado, contar com mais mulheres na política e, por outro, desencadear sua transformação. Tem se evidenciado através de pesquisas que quanto maior a quantidade de mulheres nos espaços de tomada de decisóes da política eleitoral, mais conquistas legislativas elas estão obtendo, evidenciando-se que os interesses das mulheres têm sido articulados pela maioria das parlamentares mulheres. Este fato suscita a consideração de que existe uma tendência de as mulheres, uma vez eleitas e exercendo seus mandatos na política eleitoral, potencializarem ações e pressionarem "[...] em favor de agendas que contenham temas que são de interesse 
para as mesmas" (GONZÁLEZ, 2007, p. 26), tendendo a agirem de modo substantivo e não meramente descritivo.

Contudo, levando em conta a brutal minoria que são em todos os níveis (câmaras municipais de vereadores, assembleias legislativas nos estados e Congresso Nacional), dificilmente as bancadas de mulheres conseguem aprovar projetos mais polêmicos na sociedade e que são reivindicados pelos movimentos feministas, a exemplo da descriminalização e legalização do aborto.

Não se pode perder de vista que essa defasagem de participação feminina no espaço político deve-se primordialmente aos séculos de exclusão. Tão somente durante o transcurso do século $\mathrm{XX}$, as mulheres conquistam o status de cidadâs e adquirem o direito formal de terem experiências nos âmbitos públicos. Neste sentido, Astelarra (2003, p. 30) avalia que

[...] quando as sufragistas ganharam a batalha do voto para as mulheres garantindo-lhes acesso à condição de cidadania, colocaram por terra séculos de contra posição entre as mulher e Ágora. Quando por fim se converteram em sujeitos políticos, a envergadura da ruptura foi enorme.

No cenário brasileiro, depois de 87 anos de as mulheres conquistarem o direito ao voto, persiste um profundo abismo entre mulheres e homens na política eleitoral. Sob um olhar superficial, a aparência denota que as mulheres estão em todos os lugares, atuam em áreas diversas, trabalham e recebem seus salários, podem ser lideranças comunitárias, sindicalistas ou ícones de sucesso empresarial e midiático, mas o mundo da política parece continuar sendo o principal limite.

Contudo, há que se ressaltar que, apesar de estarem nos mais diversos lugares, um olhar mais apurado irá perceber que a representatividade mantém-se majoritariamente masculina, seja nos postos de direção das empresas, nos veículos da mídia ou órgãos públicos - para além dos espaços eleitorais no legislativo e executivo, temos o Supremo Tribunal Federal, o Superior Tribunal de Justiça, o Tribunal Superior do Trabalho, o Tribunal Superior Eleitoral, e seus respectivos tribunais regionais. Ainda assim, se percebe que os espaços não político-eleitorais têm sido socialmente menos dificultosos no processo de crescimento da presença das mulheres. O mundo da política eleitoral parece ser limite.

Trata-se de lócus masculino. Socialmente criam-se justificativas: a política exige dedicação, tomaria um tempo muito grande das mulheres e tornaria complicado que elas conseguissem equilibrar bem com as demais atribuiçôes que, 
supostamente, devem ser suas prioridades, quais sejam: a família, as crianças e a vida doméstica, e aqui pode estar incluída a carreira profissional - desde que não deixe de lado família!

Pois não é outro o contexto que perdura, desde a democracia grega, em que a esfera da vida privada, o Oikos, e por consequência todas as tarefas não valorizadas socialmente, são atribuídas às mulheres, ali se ocupam e são enredadas a permanecer, juntamente com outras categorias não valorizadas daquele período, quais sejam: pessoas escravizadas, servos, crianças. Enquanto que o espaço da vida política, na Ágora, por sua vez continua sendo o local onde estáo os homens detentores de posses, ocupando, debatendo e determinando questôes fundamentais para o conjunto da sociedade.

Adquirir consciência deste cenário por coletivos de mulheres fez com que as reivindicações se tornassem, gradativamente, conquistas. $\mathrm{Na}$ avaliação de Okin (2008), por meio das análises desenvolvidas por pesquisadoras feministas, foi possível revelar a existência de múltiplas conexôes

[...] entre os papeis domésticos das mulheres e a desigualdade e segregação a que estão submetidas nos ambientes de trabalho, e a conexão entre sua socialização em famílias generificadas e os aspectos psicológicos de sua subordinação. Desse modo, a família se tornou, e vem se mantendo desde então, central à política do feminismo e um foco prioritário da teoria feminista (OKIN, 2008, p. 313).

Tal compreensão reverbera o lema "o pessoal é político", amplamente difundido nas décadas de 1960-1970 em vários países do mundo e que, segundo Okin (2008, p. 312), vai “[...] na raiz das críticas feministas à convencional dicotomia liberal público/doméstico". Ainda, questiona e problematiza os acontecimentos e a dinâmica das inter-relações do âmbito privado, estando estas atravessadas por relações de poder estruturadas socialmente, inviabilizando quaisquer interpretações isoladas do contexto daquelas relaçóes estabelecidas no espaço da vida pública. Para a autora, as esferas pública e privada foram generificadas, moldadas com papéis construídos para o domínio e supremacia masculina e para a submissão e exploração feminina. Okin indaga-se: como seria todo esse cenário em que se criou o parlamento, suas regras e funcionamento, se tivesse sido pensado por ocupantes que durante a sua vida gestam, realizam partos e são responsáveis pelos cuidados de pessoas da família? Teríamos as mesmas políticas públicas se quem decidisse por elas também fossem aquelas cujas responsabilidades diárias têm sido o cuidado dos outros? Ocorre que os homens são 
os que menos viveram e vivem essas experiências e ocupam a maioria das cadeiras nos parlamentos e, logo, definem as políticas públicas, os direitos sociais e toda gama de legislação que repousa sobre a sociedade.

No entendimento de González (2007), as mulheres adquiriram uma identidade distintiva que lhes aproxima enquanto grupo social a partir de interesses comuns que variam desde a defesa da família, igualdade de oportunidades no trabalho, acesso à educação, até questóes de violência doméstica e direitos reprodutivos. Porém, a autora chama a atenção para que essa compreensão de aproximação de interesses por parte das mulheres não remeta a equivocadas reflexóes relacionadas a

[...] outras de caráter essencialista a respeito da identidade das mulheres. Os homens e as mulheres se encontram atravessados por distintas identidades, cada uma das quais pode converter-se em dominante durante um tempo [...]. Não obstante, a variedade de identidades das mulheres não invalida o fato de que parte de seus interesses venham marcados pelo sexo. $\mathrm{O}$ argumento dos interesses não se estabelece, portanto, de acordo com uns interesses unificados das mulheres, mas sobretudo, pelas diferenças entre os interesses das mulheres e os interesses dos homens (GONZÁLEZ, 2007, p. 23).

Apesar de serem minoria, hoje as mulheres são parte da política eleitoral. Mas esse acesso, permanência e ascensão aos espaços de tomada de decisões e de poder impóe a elas um esforço muito maior e um comportamento associado a marcadores identitários masculinos. Exigem, por exemplo, das mulheres que são eleitas (ou que comandam uma empresa, uma equipe ou partido político) um nível de competência desproporcional com o que se exige aos homens que estão nesses espaços de poder e de decisão. Muitas se sentem compelidas a não expressar emoçóes ou gestos afetuosos para que não sejam confundidos com sinais de fragilidade ${ }^{2}$, pois são traços associados aos papéis de gênero construídos para serem expressos apenas na esfera privada, e devem ser evitados ao máximo quando se ocupa postos de poder.

Seria um grave equívoco partir de simplificações para buscar justificativas que demonstrem, nos marcos de sociedades democráticas contemporâneas, tão incipiente

\footnotetext{
${ }^{2}$ Essas questôes foram levantadas textualmente pelas entrevistadas da pesquisa desenvolvida para a tese de doutorado da autora.
} 
presença feminina na política eleitoral. Há uma gama de questôes que interferem na constituição deste cenário, pois, segundo Astelarra (1987, p. 161), não é possível

[...] explicar a desigualdade entre os sexos nas instituições políticas, sem fazer referências ao sistema de dominação global que exercem os homens. Se trata de uma forma de domínio que utiliza mecanismos específicos que regula as condições da presença ou ausência feminina no mundo público.

Ao se analisar separadamente as atribuiçôes diferenciadas entre gêneros nos espaços da vida privada e da vida pública, bem como sua desigual presença, incorre-se inexoravelmente ao erro, pois o sistema de gênero afeta as relações em todas as esferas. A expressão dessas desigualdades generificadas se concretiza nas mais variadas formas, sejam os sutis boicotes partidários para o êxito eleitoral das candidatas mulheres nas disputas por vagas no parlamento, por exemplo, ou as nítidas dificuldades pelas quais passam as mulheres mães quando candidatas numa disputa eleitoral e que se veem obrigadas a assumir uma carga de responsabilidade muito maior no cuidado com as crianças em comparação a homens pais quando eles são os candidatos.

É surpreendente que mesmo tendo-se passado séculos desde o advento da democracia moderna, as mulheres ainda permanecem como as principais responsáveis pelos trabalhos necessários no âmbito doméstico, ao passo que se percebe um contínuo esforço em se descredibilizar associações que façam deste espaço um lugar também de relações políticas, minimizando o exercício da cidadania e insistindo-se na manutenção do apartamento das esferas público-privada. Ao aprofundar esta análise, nota-se que

[...] não se trata de espaços com funçóes claramente diferenciadas e existências paralelas. Há uma lógica que os articula de maneira precisa. $\mathrm{O}$ âmbito público, onde se exerce cabalmente a cidadania, descansa em uma construção determinada de espaço privado. Na medida em que cada homem tem esse lugar de domínio absoluto, pode comparecer no outro espaço: das observaçóes, da concorrência, do reconhecimento, da repartição de bens. O espaço privado iguala os homens no público (FALCÓN, 2012, p. 98).

Assim, uma vez que as demandas cotidianas que perfazem o espaço privado são atribuídas às mulheres, por consequência lhes retira as potencialidades para estarem também na esfera pública. Para que se tenha uma composição democrática 
nos espaços políticos, é fundamental que se desencadeiem profundas mudanças culturais no conjunto da sociedade. É urgente amplificar essas reflexões e que estratégias sejam formuladas para esse necessário avanço na democracia.

No Brasil os movimentos feministas publicizaram o lema "o pessoal é político" durante a década de 1970, como se viu anteriormente, passando a reivindicar o cenário privado, das relações íntimas, como um espaço político. Denunciaram as violências sofridas no ambiente doméstico, os assassinatos "em legítima defesa da honra”, desencadearam debates que problematizaram a ocultação, sob a privacidade e a intimidade do lar, de questóes que afetavam e/ou colocavam em risco a vida delas.

Desta maneira, gradativamente foi se avançando aos dias de hoje na desconstrução desta separação dos âmbitos público-privado, e se questiona o nível de democracia alcançado ao se considerar o abismo existente entre os $90 \%$ de homens e os $10 \%$ de mulheres que conformam a composição dos espaços parlamentares no quadro brasileiro nacional (LOLATTO, 2016).

Contar com uma maior quantidade de mulheres na política eleitoral se justifica em razão da necessária igualdade social frente a este desequilíbrio existente entre homens e mulheres como cidadãos e sua participação em núcleos de decisão política. Ademais, as mulheres, como sujeitas políticas, também possuem a capacidade de se expressarem com voz própria. Diante disso, González (2007, p. 18) apresenta as seguintes questôes para reflexão: "É possível falar de uma contribuição distinta das mulheres na política? Existem atitudes e valores na política próprios de mulheres?”. Essas indagações serão brevemente analisadas a seguir, juntamente à importância de se pensar o empoderamento das mulheres como fator que potencializa tanto a entrada delas na política eleitoral como seus compromissos e identificação com as pautas e reivindicaçôes feministas.

\section{Representação substantiva e processo de empoderamento das mulheres}

Muitos são os desafios para se alcançar uma representação substantiva de mulheres nos espaços parlamentares de qualquer país. Tão maiores são esses desafios quando se depara com uma realidade onde sequer a representação descritiva foi alcançada. Este é o cenário brasileiro e que se tenta alterar com estratégias diversas, incluindo as alterações na legislação eleitoral como o estabelecimento de lei de contas de gênero. 
A ação afirmativa da atual Lei de Cotas (Lei no 12.034/09) (BRASIL 2009), que assegura o preenchimento mínimo de 30\% e máximo de $70 \%$ por gênero nas coligaçôes de disputas eleitorais, não se mostrou eficaz para garantir de fato a eleição das mulheres.

O sistema de cotas raramente interferiu nos processos eleitorais a ponto de distribuir o poder e a representação de forma equitativa entre os gêneros. Equivale dizer que a estratégia das cotas não incidiu sobre o patriarcado político. À conta disso, a agenda feminista, antes endereçada ao reconhecimento do direito de voto, voltou-se para as açóes afirmativas (cotas) e hoje direciona sua pauta à democracia paritária (PRÁ, 2013, p. 17).

Apesar de ainda não ter sido eficaz para aumentar consideravelmente o número de mulheres eleitas, o debate sobre a necessidade da existência da lei de cotas já contribuiu para visibilizar a exclusão da parcela feminina num dos mais importantes espaços do poder político: o parlamento. No entanto, Araújo (2012, p. 155) afirma que "[...] a exclusão da mulher da cena pública não é sinônimo de sua ausência da cena social. Ao contrário, [...] há sua inclusão nessa cena como sustentáculo da política na esfera pública". Sua leitura reforça que, para que os homens pudessem viver o espaço público da política e da cidadania, foi fundamental que as mulheres contribuíssem como parte da comunidade dos indivíduos com papéis e atributos próprios para elas, legitimando deste modo os lugares para homens e para mulheres na sociedade: eles na vida pública e elas na vida privada.

Essa dicotomia se estrutura e, de certa forma, subsiste como habitus (Bourdieu, 1989), incorporada nos atributos ou disposiçóes como inerentes [...]. Ao lado dessa tensão que transcende um único recorte e organiza a própria ideia de agente e sujeito, o constructo da cidadania foi, simultaneamente, um conjunto de dicotomias associadas ao gênero, fundamentais para justificar sua exclusão, mas estruturantes do princípio essencial (natural) de esfera pública democrática (ARAÚJO, 2012, p. 155).

Assim, o debate de cotas, impulsionado internacionalmente na década de 1990, potencializou, antes de mais nada, a reflexão sobre esses lugares construídos histórica e culturalmente para serem ocupados por homens/por mulheres público/privado, como se destacou no primeiro item. 
Existem vários estudos comparativos que aprofundam as análises das leis de cotas, suas aplicaçóes e impactos em vários países do mundo em relação ao avanço das mulheres no espaço da política partidária ${ }^{3}$. No entendimento de Palma (2012, p. 125) "[...] as cotas reforçam a representação descritiva; a maior presença numérica da mulher traz maior visibilidade pública e, muito provavelmente, as empodere socialmente".

Para Palma (2012) a representação descritiva vincula-se à quantidade numérica, bastante importante do ponto de vista da democracia de gênero, enquanto a representação substantiva se relaciona com o comportamento legislativo das pessoas eleitas em se posicionar na defesa de determinados segmentos da sociedade ${ }^{4}$.

A questão que infere nisso é o fato de que nem todas as mulheres que conseguem ser eleitas são feministas, possuem consciência da histórica opressão do sistema patriarcal, ou conhecem os debates sobre a igualdade/equidade de gênero. Mesmo que se considere por si só a eleição de mulheres como avanço do ponto de vista democrático, é fundamental impulsionar ações dirigidas aos parlamentos que atualizem as demandas feministas em torno das discriminaçôes e violências de gênero que ainda afetam a vida das mulheres em geral e de modo particular.

Certamente, nos marcos do atual contexto político brasileiro, seria impossível que acontecesse por parte de todas as parlamentares sua identificação com o feminismo. Gómez-Ramírez e Cruz (2008, p. 389) argumentam que, mesmo sendo inegáveis as conquistas alcançadas por este movimento social para a vida cotidiana das mulheres, o estigma que carrega o vocábulo "feminista" embaralha e torna as pessoas "cegas" diante da "[...] iniquidade existente entre homens e mulheres a luz do que

\footnotetext{
${ }^{3}$ Entre eles temos os trabalhos de Pippa Norris (2006), Nelida Archenti e María Inés Tula (2008), e María del Rosario Zúñiga (2013).

${ }^{4}$ Junto ao debate em torno da representação descritiva e substantiva, há o debate acerca da política de presença e da política de ideias. Tendo em vista as limitaçóes objetivas para estendermos essas reflexóes neste artigo, sucintamente aludimos que para Anne Phillips (2001) a política de presença refere-se à representação das múltiplas identidades, de cada agrupamento social, desde os mais densos até os menores contingentes populacionais; segundo a autora, defender a política de presença, pensando unicamente no sexo - homens-mulheres - implica uma posição antidemocrática frente à pluralidade das identidades no contexto da modernidade e pós-modernidade. A política de ideias mostra-se mais plausível, enfatiza Phillips (2001), por tratar mais das reivindicaçóes de segmentos diferentes e subrepresentados do que da presença de todos numa esfera da política eleitoral. Para aprofundar especialmente esse debate, recomenda-se a leitura de Phillips (1996 e 2001).
} 
outras feministas já conquistaram para nós, como o direito legal ao voto e a educação".

Em que pesem as tantas conquistas obtidas pelo feminismo, as mulheres continuam sofrendo uma série de discriminações que são encobertas pelo "véu da igualdade", de tal forma que "[...] essa suposta igualdade entre homens e mulheres é usada como um dos argumentos mais frequentes para não envolver-se nem reivindicar-se feminista" (GÓMEZ-RAMÍEZ e CRUZ, 2008, p. 390). Neste sentido,

[...] o vocábulo e, mais além, seu conteúdo, gera muita resistência. Os prejuízos e as desqualificaçóes estão espalhados; não existe uma consciência clara sobre as razóes do que e para que serve ser feminista. A concepção negativa das feministas é forte, e tudo isso se deve a enorme desinformação a respeito [...]. O rumor indica que as feministas são anti homens, abortistas, libertinas, ameaçantes. Como o feminismo é equiparado com o machismo, se pensa naquele como um machismo ao inverso (GÓMEZ-RAMÍREZ e CRUZ, 2008, p. 392).

Portanto a náo identificaçáo com o feminismo por grande parte das parlamentares eleitas, quando analisada diante de um contexto social e cultural adverso mesclado ao baixo percentual de assentos por elas ocupados, chega a ser até compreensível (GÓMEZ-RAMÍREZ e CRUZ, 2008). Este vocábulo mexe com a subjetividade das pessoas, principalmente daquelas mulheres que ainda não despertaram para uma tomada de consciência em relação às desigualdades de gênero tão enraizadas na sociedade.

Além disso, para muitas parlamentares, assumir-se feminista implica perder o apoio de seu eleitorado de origem, que pode ser conservador e avesso ao feminismo. Mais do que um ato irrefletido, 'se ver e se aceitar feminista' implica um lento e conflituoso processo,

[...] já que o ambiente em que este se desenvolve é hostil. A reconstrução da identidade feminina é dolorosa, posto que implica a confrontação consigo mesma. As contradiçóes se experimentam quando as jovens percebem que as coisas lhes marginalizam, lhes anulam, oprimem e excluem cotidianamente e, ao mesmo tempo, elas não possuem elementos para enfrentar o contexto. [...] Também se pode optar por uma postura de comodidade, em que não se confronte a família, o marido ou a realidade imperante. Por isso, muitas delas tomam consciência e se manifestam em desacordo, ou seja, tem uma resistência 
passiva e não se encaminham para a resistência ativa (GÓMEZRAMÍREZ e CRUZ, 2008, p. 394).

Como alternativa para potencializar a identificação com o feminismo, poderiam ser desenvolvidas atividades de formação voltadas para mulheres que almejam candidatarem-se a cargos políticos, possibilitando-as participar de discussões sobre temáticas que abordem a origem das opressóes, o surgimento dos movimentos feministas, seu papel na conquista das principais reivindicaçôes das mulheres, a divisão sexual (ou social) do trabalho, e sugerir iniciativas legislativas que visem melhorar as condiçôes de vida das mulheres. Tais alternativas podem ser vistas como parte de um feminismo estratégico que, segundo Escalera (2013), se propõe a reativar falas de saberes submetidos e dessujeitar-se da dominação masculina e da apropriação de um discurso como verdade única. Neste sentido, o processo de empoderamento sob a perspectiva feminista apresenta às mulheres uma

[...] nova concepçáo de poder, assumindo formas democráticas, construindo novos mecanismos de responsabilidades coletivas, de tomada de decisóes e responsabilidades compartilhadas proporcionando um maior nível de 'bem-estar', maior grau de participação e acesso ao controle das políticas públicas que venham ao encontro de suas necessidades (LISBOA, 2007, p. 651).

Para as mulheres em geral que vivem a experiência de ser parlamentar, este "chegar lá" implicou certamente seu envolvimento num processo de empoderamento, compreendido por León (2000, p. 192) como uma tomada de açóes, por meio do qual "[...] o sujeito se converta em agente ativo como resultado de um acionamento, que varia de acordo com cada situação concreta". As mulheres que assumem esses espaços na política eleitoral e ocupam um assento no parlamento precisam desenvolver um senso de coragem para cotidianamente estarem ali enfrentando hostilidades peculiares e inúmeras tensões próprias do mundo da política.

As origens do conceito de empoderamento, conforme Iorio (2002), têm suas raízes nos movimentos negros e feministas dos Estados Unidos na década de 1960. Porém,

[...] é na interseção com gênero que o conceito de empoderamento se desenvolve tanto em nível teórico como instrumento de intervenção na realidade. Nos anos 1970 e 1980, feministas e grupos de mulheres 
espalhadas pelo mundo desenvolveram um árduo trabalho de conceitualização e de implementação de estratégias de empoderamento, com o qual buscaram romper com as diferentes dinâmicas que condicionavam a existência e impediam a participação e a cidadania plena das mulheres (IORIO, 2002, p. 21).

Empoderamento, para Lisboa (2007, p. 642) - apoiada na obra de John Friedman de 1996 - envolve "[...] todo acréscimo de poder que, induzido ou conquistado, permite aos indivíduos ou unidades familiares aumentarem a eficácia do seu exercício de cidadania”. No desenvolvimento de sua reflexão são levantados três tipos centrais de empoderamento: social, político e psicológico.

O empoderamento social pressupóe o acesso a informaçóes, técnicas, conhecimento, recursos financeiros e a participação social, diz respeito à garantia da sobrevivência e independência econômica. $\mathrm{O}$ político vai além do voto, significa ter o poder de voz e ação coletiva, implica maior participação na política, em espaços de representação e direção. E o poder psicológico se manifesta na autoconfiança e consciência individual, grande parte das vezes é o resultado de uma ação vitoriosa nos domínios do social ou político e também pode ser resultado do trabalho intersubjetivo.

Estes três tipos de poder devem se integrar numa tríade. Quando esta tríade, centrada numa mulher ou numa unidade doméstica, está ligada a outras, o resultado é uma rede de relaçóes de empowering que, devido ao esforço mútuo, tem um potencial extraordinário de mudança social. As mulheres que trabalham com outras mulheres [...] podem alcançar muito mais resultados que uma mulher trabalhando só (LISBOA, 2007, p. 642).

As reflexôes de Lisboa (2007) e Lolatto (2016) denotam que mulheres que assumem um posto de comando ou mandato parlamentar passam (ou já passaram) por um processo de empoderamento social, psicológico e político. Tal processo envolve o desenvolvimento de capacidades, individuais e coletivas, para superar situaçóes-problema, sejam de ordem socioestruturais ou no micro espaço do cotidiano.

Há cinco momentos do processo de empoderamento, segundo Lisboa (2007), a partir de Kieffer, caracterizando a passagem de uma situação de impotência para competência participativa: a) o contexto: a experiência de uma ruptura ou ameaça vital, a percepção da opressão, acompanhada por um sentimento de inconformismo, 
de "[...] não aceitação, e, ao mesmo tempo de competência para a participação, ou seja, a pessoa passa a sentir que está apta para agir em prol de uma transformaçáo” (LISBOA, 2007, p. 645); b) a motivação: percebe que não está só, junta-se a outras pessoas que vivem situação similar e passa a ter uma visão crítica das estruturas de poder vigentes; c) engajamento e reivindicação: é a mobilização a partir da fase crítica, onde reaçôes espontâneas evoluem para um engajamento estável produzindo vínculos duradouros numa dimensão coletiva e não mais individual; d) integração e ação: quando os conflitos são compartilhados com a participação em grupos diversos, originando o sentimento de pertencimento, trocas mútuas e redes de sociabilidade; e) a conscientização: a partir da perspectiva de Paulo Freire, "[...] uma consciência política, ou seja, 'sentir-se capaz', ter o poder de 'fazer' algo como sujeitos ativos do processo de transformação na perspectiva de um outro tipo de desenvolvimento" (apud LISBOA, 2007, p. 646).

Destaca-se, ainda, os níveis de empoderamento, quais sejam: o individual, o grupal e o estrutural. No primeiro nível, a pessoa consegue romper com situaçôes de dominação que afetam a si diretamente e toma a condução de sua vida. No nível grupal esta pessoa envolve-se em grupos com a mesma proposta política e passa a integrar um coletivo e trocar a experiências. No terceiro nível, o estrutural, acontece uma adesão a organizaçôes coletivas, inserção em movimentos sociais ou partidos políticos ou grupos no interior desses partidos a fim de enfrentarem, por vezes sem dar-se conta desse contexto, toda uma estrutura que opera para manter um sistema de dominação. Neste sentido,

[...] o empoderamento, implica na inversão dos mecanismos de poder patriarcais fundados na opressão e na mudança de normas, crenças, mentalidades, usos e costumes, práticas sociais e conquista dos direitos da mulher. Trata-se de um poder das mulheres conformado por um conjunto de suportes, recurso e condiçóes vitais: 'é o poder para viver sem o risco que hoje significa a vulnerabilidade de gênero; [...] poder para intervir com paridade em todas as decisóes e assuntos do mundo; [...] poder de protagonizar cada uma a sua vida e de serem reconhecidas como gênero, como um sujeito histórico' [...]. Para que essa nova concepção de poder possa ser colocada em prática, é necessário que aconteçam mudanças estruturais profundas (LISBOA, 2007, p. 644).

Analisando o empoderamento das mulheres na relação com as disparidades globais de gênero, Lopez-Claros e Zahidi (2005), ao avaliarem padróes de 
desigualdades entre os gêneros, elencam cinco dimensóes que devem ser consideradas para um maior empoderamento das mulheres: 1. participaçáo econômica, que diz respeito à remuneração e presença das mulheres no mercado de trabalho; 2 . oportunidade econômica, que considera a qualidade do trabalho e avalia os guetos onde concentra-se a feminização da pobreza e do trabalho precário; 3 . empoderamento político, que relaciona a representação de mulheres nas estruturas de tomada de decisóes e seu direito de voz para formular políticas para a sociedade da qual fazem parte; 4. avanço educacional como dimensão fundamental para o empoderamento de todas as esferas da sociedade; e, 5. a saúde e o bem-estar das mulheres, para além da "vida reprodutiva", abarcando as situações de violências vividas pelas mulheres nos mais variados lugares de circulação. Essas cinco dimensões são importantes para avaliar o grau de desigualdade e empoderamento real das mulheres de um país, estado ou município.

Cabe ressaltar que, em relação ao cenário de participação política das mulheres, este estudo enfatiza que

[...] a ausência de mulheres nas estruturas de governo significa inevitavelmente que prioridades nacionais, regionais e locais - isto é, como os recursos são alocados - são definidas sem participação significativa de mulheres, cuja experiência de vida em relação aos homens proporciona a elas uma compreensão diferenciada das necessidades, preocupaçóes e interesses. [...] Para mudar prioridades de gasto e de desenvolvimento, torna-se fundamental a representação de uma massa crítica de mulheres que estão aprendendo, usando e mudando as regras do 'jogo' de tomada de decisão e, dessa forma, obtendo impacto no discurso e tomada de decisóes em todos os níveis (LOPES-CLAROS e ZAHIDI, 2005, p. 11).

O processo de empoderamento está associado necessariamente à participação, contudo a grande maioria das mulheres precisa empoderar-se primeiramente na esfera privada, do âmbito das relações intrafamiliares, para ter condições de participar dos espaços públicos. Conforme analisa León (2000, p. 203), “[...] o processo de empoderamento é, para as mulheres, um desafio junto a ideologia patriarcal com vistas a transformar as estruturas que reforçam a discriminação de gênero e a desigualdade social". Dentre essas estruturas destacam-se a lógica da divisão sexual do trabalho que atribuiu papéis diferenciados baseados no gênero, a secular cultura que separa de forma radical as esferas pública e privada, os sistemas políticos e eleitorais e 
suas normatizaçôes que dificultam a entrada e permanência das mulheres nesse espaço.

Enfrentar essas estruturas, longe de ser tarefa fácil, mostra-se como necessária e urgente para que seja possível construir uma nova realidade, uma fotografia diferente e que reflita o conjunto majoritário da sociedade brasileira composta por mais mulheres do que homens, mais negros do que brancos, mais trabalhadores do que empresários, mais pequenos agricultores do que fazendeiros do agronegócio. Nitidamente se denota que a perda de direitos sociais e trabalhistas está ligada a uma maioria substantiva, que defende seus interesses no Congresso Nacional e, consequentemente, atinge o gênero, a cor e a classe daqueles imensos contingentes populacionais que são historicamente explorados, excluídos e oprimidos.

\section{Considerações finais}

As mulheres, há séculos, buscam estratégias para superar as mais diferentes formas de discriminaçôes. O direito de estudar, de votar e de ser votada, no Brasil, foi uma conquista que as mulheres obtiveram somente no século $\mathrm{XX}$, mesmo século em que se difundiram os movimentos feministas. Se for feita uma comparação entre as normatizaçôes sociais de comportamento das mulheres em 1918 e a realidade de 2018, é inconteste que houve avanços: elas passaram a ocupar espaços públicos em busca de direitos iguais na lei e na vida. O que não significa ter alcançado de fato as condições de igualdade.

O histórico alijamento das mulheres do âmbito público e a persistência de uma cultura machista refletem de várias formas na sociedade contemporânea. $\mathrm{O}$ conjunto de fatores elencados neste artigo gera o retrato da esfera político-eleitoral distante de uma democracia de gênero, em que $89,5 \%$ dos parlamentares são homens e apenas $10,5 \%$ são mulheres em uma nação composta por $51,5 \%$ de mulheres e $48,5 \%$ de homens (IBGE, 2018).

Pela ótica da democracia de gênero, a eleição de mulheres é importantíssima, pois implica em acessar um espaço historicamente negado e ainda de difícil êxito e permanência. Para tanto, o processo de empoderamento de cada uma e de coletivos de mulheres é longo e não é natural, necessita que gatilhos sejam acionados.

$\mathrm{O}$ fato de muitas mulheres eleitas apresentarem resistência ou desconhecimento das reivindicaçóes feministas, das demandas específicas de políticas públicas para as mulheres, dificulta que se avance com maior agilidade na efetivação e real garantia de mais direitos e políticas de equidade de gênero. Porém, não se pode 
ter a pretensão de que todas as mulheres eleitas tenham, previamente, conhecimento e compromisso com as pautas dos movimentos feministas. Cabe a esses movimentos criar estratégias para que a representação descritiva se torne também substantiva.

O desafio de eleger mais mulheres identificadas com o feminismo, comprometidas com o avanço de políticas públicas para melhorar a vida das mulheres e dos segmentos historicamente oprimidos, se associa à persistência em continuar reivindicando condiçóes de igualdade na sociedade, seja no ambiente doméstico, no mundo do trabalho ou nos partidos políticos, assim como a um sistema eleitoral mais democrático e equitativo.

Simone Lolatto é Assistente Social, Doutora em Ciências Humanas pela Universidade Federal de Santa Catarina, integrante do NUSSERGE - Núcleo de Estudos e Pesquisas em Serviço Social e Relações de Gênero. E-mail: lolatto1810@gmail.com.

\section{Referências}

ARAÚJO, Clara. Cidadania democrática e inserção política das mulheres. Revista Brasileira de Ciência Política, n. 9, p. 147-168, 2012.

ARCHENTI, Nelida; TUlA, María Inés (Eds). Mujeres y política en América Latina. Sistemas electorales y cuotas de género. Buenos Aires: Heliasta, 2008.

ARENDT, Hannah. Entre o Passado e o Futuro. Tradução de Mauro W. Barbosa. São Paulo: Perspectiva, 2009.

ASTELARRA, Judith. Democracia, Género y Sistema Político. In: MEENTZEN, Angela e GOMÁRIZ, Enrique. Democracia de Género, una propuesta inclusiva - contribuciones desde América Latina y Europa. El Salvador: Fundación Heinrich Böll, 2003. p. 26-39.

. La cultura política y las mujeres. In: LECHNER, Norbert (Comp.). Cultura política y democratización. Santiago do Chile: Salesianos, 1987. p. 149-168.

BRASIL. Lei no 12.034, de 29 de setembro de 2009. Altera as Leis nos 9.096, de 19 de setembro de 1995 - Lei dos Partidos Políticos, 9.504, de 30 de setembro de 1997, que estabelece normas para as eleições, e 4.737, de 15 de julho de 1965 - Código Eleitoral. Diário Oficial da União, 30 set. 2009.

CASTRO, Mary Garcia. Alquimia de categorias sociais na produção dos sujeitos políticos. Estudos Feministas, v. 0, n. 0, p. 57-73, 1992.

ESCALERA, Ana Maria Martinez de la. Feminismo: un uso estratégico de vocabulário. México: PUEG, UNAM, 2013. 
FALCÓN, Marta Torres. El principio de igualdad y las acciones afirmativas. Un análisis desde los derechos humanos. In: SERRET, Estela (Coord.). Democracia y Ciudadania: perspectivas criticas feministas. Suprema Corte de Justiça da Nação, México: Fontamara, 2012. p. 93-120.

GÓMEZ-RAMÍREZ, Oralia; CRUZ, Luz Verónica Reyes. Las jóvenes y el feminismo: ¿Indiferencia o compromiso? Revista Estudos Feministas, ano 16, n. 2, p. 387-408, maio-ago. 2008.

GONZÁLEZ, Marta Lois. Mujeres y toma de deciones. Una aproximación de la literatura especializada. In: OTERO, Isabel Diz y GONZÁLEZ, Marta Lois (Eds.). Mujeres, Institucines y Política. Barcelona: Ediçóes Bellaterra, 2007. p. 17-45.

INSTITUTO BRASILEIRO DE GEOGRAFIA E ESTATÍSTICA (IBGE). Estatísticas de Gênero indicadores sociais das mulheres no Brasil. [S.1.]: IBGE, 2018. Disponível em: <https://www.ibge.gov.br/estatisticas/multidominio/genero/20163-estatisticas-de-generoindicadores-sociais-das-mulheres-no-brasil.html?=\&t=o-que-e>. Acesso em: 21 ago. 2018.

IORIO, Cecília. Algumas consideraçôes sobre estratégias de empoderamento e de direitos. In: ROMANO, Jorge O.; ANTUNES, Marta (Org.). Empoderamento direitos no combate à pobreza. Rio de Janeiro: ActionAid Brasil, 2002. p. 21-44.

LEÓN, Magdalena. Empoderamiento: relaciones de las mujeres con el poder. Revista Estudos Feministas, ano 08, n. 2, p. 191-205, jan. 2000.

LISBOA, Teresa Kleba. Empoderamento de mulheres e participação na gestão pública. In: II Seminário Nacional Movimentos Sociais, Participação e Democracia. Anais do II Seminário Nacional Movimentos Sociais, Participação e Democracia. Florianópolis: Núcleo de Pesquisa em Movimentos Sociais, UFSC, 2007. p. 640-652.

. Gênero, classe e etnia - trajetórias de vida de mulheres migrantes. Florianópolis: Ed. da UFSC; Chapecó: Argos, 2003.

LOLATTO, Simone. Mulheres na Política: trajetórias das vereadoras titulares em Florianópolis/SC. 2016. 348 p.Tese (Doutorado em Ciências Humanas) - Programa de Pós-Graduação Interdisciplinar em Ciências Humanas, Universidade Federal de Santa Catarina, Florianópolis, 2016.

LOPEZ-CLAROS, Augusto; ZAHIDI, Saadia. Empoderamento das mulheres. Avaliação das disparidades globais de gênero. In: Fórum Econômico Mundial. Tradução de José Humberto Fagundes. Suíça: UNIFEM - Fundo de Desenvolvimento das Naçóes Unidas para a Mulher, 2005. p. 01-30.

NORRIS, Pippa. "Recruitment”. In: KATZ, Richard; CROTTY, Willian (Eds.). Handbook of Party Politics. Londres: Sage, 2006.

OKIN, Susan Moller. Gênero, o público e o privado (1991). Revista Estudos Feministas, ano 16, n. 2, p. 305-332, 2008.

PALMA, Esperanza. Candidaturas femeninas y reclutamiento legislativo en México: el impacto de las cuotas de género en la composición de la LXI legislatura. In: SERRET, Estela (Coord.). Democracia y Ciudadanía: perspectivas críticas feministas. México, Suprema Corte de Justicia de la Nación, 2012. p. 121-145.

PATEMAN, Carole. The sexual contract. Stanford: Stanford University Press, 1988.

PHILLIPS, Anne. De uma política de ideias a uma política de presença? Revista Estudos Feministas, v. 9, n. 1, p. 268-290, 2001. 
PHILlIPS, Anne. Gênero y Teoria Democrática (1991). Tradução de Isabel Vericat. México: Filipinas, 1996.

PINAFI, Tânia. Violência Contra a Mulher: políticas públicas e medidas protetivas na contemporaneidade. Histórica - revista on line do Arquivo Público de São Paulo, ano 3, n. 21, p. 17-25, 2007.

PRÁ, Jussara Reis. Cidadania de Gênero, Democracia Paritária e Inclusão Política das Mulheres. Gênero na Amazônia, v. 4, p. 15-35, 2013.

SCOTT, Joan W. Gênero: uma categoria útil de análise histórica. Revista Educação e Realidade, v. 20, n. 2, p. 71-99, 1995.

ZÚNIGA, María del Rosario Varela. A 10 años de la cuota de género en el estado de Coahuila: del desencanto a la incertidumbre pasando por la esperanza. In: GARCIA, Maria Aidé Hernández; ALONSO, Jesús Alberto Rodríguez (Coord.). Entre guijarros: avances y retrocesos de la participación política de las mujeres en México. México: Porrúa, 2013. p. 131-154.

Texto recebido em 16 de dezembro de 2018. Aprovado em 15 de outubro de 2019. 